\title{
Estatísticas e Políticas Públicas ORIENTADAS POR EVIDÊNCIAS NO BRASIL: O CASO DAS POLÍtICAS DE DESENVOLVIMENTO SOCIAL NOS ANOS 2000*
}

\author{
Paulo de Martino Jannuzzi \\ Escola Nacional de Ciências Estatísticas
}

\section{Resumo}

\begin{abstract}
A tese central deste texto é mostrar como a produção regular e a ampla disponibilidade de Estatísticas Públicas, em particular, dos Indicadores Sociais construídos a partir da Pesquisa Nacional por Amostra de Domicílios (PNAD), cumpriram papeis importantes na agenda de combate à fome e na Política de Desenvolvimento Social no país, ao aportar insumos para defesa da sua relevância, desenho, monitoramento e avaliação dos seus programas. Inicia-se com uma recensão sobre 0 surgimento dos Indicadores Sociais em meio à estruturação do Estado de Bem-Estar ao longo do século XX. Em seguida, apresenta-se como a PNAD foi se transformando em uma pesquisa com escopo temático cada vez mais amplo e aderente às preocupações do Estado e Sociedade brasileiros, e como as informações levantadas na pesquisa foram sendo empregadas na Política de Desenvolvimento Social e seus programas no país. À guisa de conclusão, advoga-se pela necessidade de uso mais bem informado e plural das estatísticas pela mídia brasileira, pelos riscos de crescente deslegitimação de políticas e programas constituintes da trilha civilizatória inscrita na Constituição Federal de 1988.
\end{abstract}

Palavras-chave: Estatísticas Públicas, Políticas Sociais, Indicadores, Avaliação de Políticas.

\begin{abstract}
The main point of this text is to show how the regular production and the wide availability of Public Statistics, in particular, of the Social Indicators constructed from the National Household Sample Survey (PNAD), have played important roles in the anti-hunger agenda and in the Social Development Policy in the country, by providing information to defend its relevance, design, monitoring and evaluation of its programs. It begins with a review on the emergence of the Social Indicators besides Welfare State building in 20th century. Then, it is presented how the PNAD was transformed into a broader thematic scope survey, connected to the concerns of the Brazilian State and Society, and how the information raised has being used to Social Development Policy and its programs in the country. As a conclusion, we advocate the need for a more informed and plural use of statistics by the Brazilian media, for the risks of increasing delegitimization of policies and programs that constitute the civilizatory track inscribed in the Federal Constitution of 1988.
\end{abstract}

Key words: Public Statistics, Social Policies, Indicators, Policy Evaluation.

\section{Apresentação}

E

m um país com tantas descontinuidades político-administrativas, desvalorização de suas instituições públicas e deslegitimação do Estado, não podem deixar de ser comemorados "marcos republicanos" como os oitenta anos do IBGE (em 2016), os cinquenta anos da Pesquisa Nacional por Amostra de Domicílios (em 2017), os quarenta anos da publicação Indicadores Sociais (em 2019) e os cento cinquenta anos de Censos Demográficos (em 2022). O IBGE, suas pesquisas e publicações tem trazido contribuições fundamentais ao acompanhamento das mudanças econômicas, sociais e demográficas e ao processo de formulação, monitoramento 
e avaliação de políticas públicas do Brasil. A produção científica nas Ciências Sociais Aplicadas é relevadora da importância e contribuição de Censos Demográficos, Censos Agropecuários, Estatísticas do Registro Civil, Pesquisas de Informações Municipais e Pesquisas Econômicas para desvelamento das transformações que o país tem passado nesse período. Não houvesse tais pesquisas e registros estatísticos, a produção de conhecimento empírico acerca da realidade brasileira certamente seria muito menor e muito menos aprofundada, assim como também seria incomensuravelmente mais baixa a efetividade da ação pública no equacionamento e mitigação dos grandes problemas nacionais.

Fato é que, não fosse o portfólio variado de levantamentos estatísticos disponíveis no Brasil, a natureza pública e regularidade da produção das mesmas pouco se conheceria sobre a mudança social ao longo do século XX no Brasil e, em especial, após a Constituição de 1988. Essas estatísticas públicas permitiram documentar - com as virtudes e os vieses dos instrumentos de pesquisa de cada época, como bem assinalou Oliveira (2003) - parte significativa da história social e econômica do Brasil Republicano de forma certamente muito mais detalhada, precisa e plural que os relatos de viajantes estrangeiros do século $\mathrm{XVI}$, os registros paroquiais de nascimentos e óbitos e a contabilidade imprecisa de produtos de exportação nos séculos permitiram reconstituir a história do Brasil Colônia e Brasil Império.

Contribuir para investigação nessa temática no período mais recente, em uma perspectiva ensaística, é o objetivo desse texto. Mais especificamente, a tese aqui discutida é que a produção regular e a ampla disponibilidade de Estatísticas Públicas, em particular, dos Indicadores Sociais construídos a partir das mesmas, foram essenciais para proposição, desenho e efetividade das políticas públicas sociais nos últimos cinquenta anos. O que se advoga nesse texto é que as estatísticas e indicadores, na sua regularidade temporal e pluralidade temática, cumpriram papel muito relevante na defesa da prioridade política, nos esforços de implementação de programas e na obtenção de resultados das políticas sociais. Ainda que não suficientes, os Indicadores Sociais foram cruciais para a especificação e implantação de políticas públicas que lograssem a universalização da educação infantil e ensino fundamental, a mitigação da fome e insegurança alimentar, a inserção laboral mais qualificada para segmentos expressivos da força de trabalho, o acesso à Proteção Social por larga maioria da população idosa ou vulnerável, para citar alguns dos resultados da agenda das políticas públicas "contratadas" desde a Constituição de 1988.

Se capacidade de gestão fez diferença na produção das políticas públicas nessas últimas décadas - tese que precisa ser mais investigada - parte dessa capacidade deve ser atribuída ao potencial analítico que estatísticas produzidas pelo IBGE e outras instituições colocaram à disposição para agentes públicos nos três níveis de governo. Ou, alternativamente, como é a hipótese aqui apresentada: se os técnicos e gestores públicos não dispusessem de informação estatística de boa qualidade nos últimos anos, a efetividade das políticas públicas teria sido diferente; certamente menor.

Naturalmente, não se pretende advogar uma tese ingênua, de iluminismo técnico por parte do IBGE e outras instituições, como se a relação entre Sistema Estatístico e Políticas Públicas fosse unidirecional, de uma quase autonomização das Estatísticas frente ao Estado. Na realidade, ao contrário, as Estatísticas refletem o estágio de estruturação do Estado de Bem-Estar, a complexidade da base e relações econômicas e conjunto de preocupações societais a cada momento histórico. Como já advertia Miles (1985) há algumas décadas, estatísticas e indicadores 
não podem ser entendidos como instrumentos neutros, livres de valores ideológicos ou políticos. Objetividade técnica-científica não é absoluta, mas socialmente construída. Se é fato que são as Políticas Públicas que pautam - com maior ou menor rapidez - o Sistema Estatístico, este contribui para aprimorar a ação governamental, pelo desvelamento de realidades socioeconômicas nos diagnósticos em diferentes escalas e pela avaliação dos efeitos, defeitos ou não efeitos das políticas e programas.

A investigação acerca das conexões entre Sistema Estatístico e Políticas Públicas é ainda um campo a desenvolver no país, em que pesem os esforços meritórios de pesquisa de alguns autores e os registros institucionais que o Centro de Documentação e Disseminação de Informações do IBGE vêm publicando nesse campo nas últimas décadas ${ }^{1}$. Este texto agrega-se a esse programa de investigação, ao se debruçar sobre a contribuição dos Indicadores computados a partir da Pesquisa Nacional por Amostra de Domicílios (PNAD) para subsidiar as Políticas de Desenvolvimento Social nos últimos 15 anos. Configura-se, assim, como um caso ilustrativo de Evidence-based policy making, explicitando como a Informação Estatística foi apropriada no processo de agendamento, formulação e avaliação de políticas públicas e como esse processo influenciou a pauta de investigação do IBGE.

O texto está estruturado em duas seções, além dessa apresentação e da conclusão. Iniciase com uma recensão sobre o surgimento dos Indicadores Sociais nos últimos setenta anos, e como esse processo se relaciona com a consolidação do Estado de Bem-Estar, em suas variadas conformações, pelo mundo afora e no Brasil. Discorre-se em seguida sobre como a PNAD foi se transformando em uma pesquisa com escopo temático cada vez mais amplo e aderente às preocupações do Estado e Sociedade brasileiros, em especial como as informações da pesquisa foram sendo empregadas para aprimoramento das Políticas e Programas de Desenvolvimento Social nos últimos quinze anos. À guisa de conclusão, discorre-se sobre os riscos da "midiotização" das Estatísticas e das Políticas Públicas e seus efeitos na deslegitimação da ação governamental e da capacidade técnica-burocrática no país.

\section{Estatísticas e as Políticas Públicas no Estado Contemporâneo}

Estatísticas são, como a etimologia da palavra releva, assuntos - fatos e dados - acerca do Estado. Se foram fundamentais para constituição do Estado Moderno, no dimensionamento da população dos países e de seus exércitos, na extensão de suas fronteiras e da cobertura da base tributária, as estatísticas reelaboradas na forma de indicadores cumprem, para o Estado Contemporâneo, desígnios mais abrangentes, civilizatórios e certamente mais complexos.

Ao longo do último século, a ampliação do escopo e a regularidade da produção de estatísticas públicas e indicadores acompanharam pari-passu o fortalecimento do Estado e das políticas públicas pelo mundo afora. Até final do século XIX, as estatísticas demográficas (população e mortalidade) e de comércio exterior eram suficientes para a gestão do então Estado Regulador e suas funções de administração da justiça, manutenção da burocracia de arrecadação

\footnotetext{
${ }^{1}$ Vide, entre outros, Oliveira (2003), Oliveira e Simões (2005), Senra (2005), Senra (2017) e Jannuzzi (2017).
} 
tributária, de provimento de segurança interna e defesa nacional. A este Estado, com essas funções, bastava uma carga fiscal não muito superior a 10\% do Produto Interno Bruto (PIB), como mostra Tanzi (2005). Ao longo do século XX, nos países hoje desenvolvidos, novas demandas coletivas e responsabilidades públicas foram sendo incorporadas ao Estado, levando a estruturação do Estado de Bem-Estar em diferentes modelos como o Nórdico Socialdemocrata, Anglo-Saxão Liberal, Continental Conservador e Mediterrâneo "Familista", na tipologia proposta por Moreno et al (2014) a partir da proposta clássica de Esping-Andersen (1991). Assim, no período entre a Guerras Mundiais a carga fiscal média dos Estados europeus já estava acima de $20 \%$ do PIB, vindo a superar os $30 \%$ do PIB no pós-guerra, ampliando-se durante os "Anos Dourados do Capitalismo", entre 1950 e meados dos anos $1970^{2}$.

Dados mais recentes, da presente década, compilados pelo Fundo Monetário Internacional (MAURO et al, 2013), mostram que o Estado Contemporâneo no mundo desenvolvido requer de $35 \%$ a $55 \%$ do PIB para seu financiamento, conforme amplitude setorial e cobertura populacional das políticas públicas e, naturalmente, conforme nível de coesão, desigualdade e bem estar social desejado pela sociedade. Para esse Estado Contemporâneo, mesmos para países com pautas mais restritivas de Políticas Públicas - como em países assentados em sistemas de bem-estar típicos do Estado Liberal Anglo-Saxão - o escopo de estatísticas públicas é muito mais amplo que no passado, refletindo o processo histórico de produção de informação para tratar de agendas públicas cada vez mais adensadas.

De fato, da década de 1920 ao final dos anos 1990, sucederam-se diferentes ênfases da produção das estatísticas e indicadores econômicos, sociais e ambientais, decorrência direta das problemáticas que os Estados Nacionais tiveram que enfrentar como consequência dos flagelos das guerras mundiais e novas questões sociais decorrentes da urbanização e do avanço do capitalismo (Figura 1). De um lado, pela ação de sindicatos e de movimentos sociais (feminista, negro, minorias etc.) e, sobretudo, pela institucionalização dos mecanismos de representação democrática - voto universal, representação política, partidos políticos - o Estado passou a ser pressionado a atender demandas coletivas cada vez mais abrangentes. Aos pleitos pela proteção aos riscos de desemprego, acidentes de trabalho e da perda da capacidade laboral da população idosa, foram se agregando às demandas por acesso à educação básica, aos serviços de saúde, aos serviços socioassistenciais e, inclusive, em vários países, à moradia subsidiada. De outro lado, recursos públicos foram demandados para atender as necessidades de financiamento da infraestrutura física para viabilização do crescimento industrial e, mais recentemente, para lidar com as externalidades ambientais decorrentes desse crescimento e da exploração dos recursos naturais.

Países com Sistemas de Proteção Social tão diferentes como os EUA, Alemanha, Espanha e Suécia precisaram, pelo menos até os anos 1970, recolher parcelas crescentes do PIB para

\footnotetext{
${ }^{2}$ A carga fiscal - somatória dos tributos arrecadados pelas esferas de governo, assim como as isenções fiscais, como parcela do PIB - é um indicador síntese - ainda que imperfeito - para retratar os diferentes modelos de Estado de BemEstar. O uso desse indicador nesse texto se justifica por sua simplicidade argumentativa entre necessidades de financiamento do Estado e as demandas por informação estatística. Na realidade, mais do que a carga fiscal, os citados modelos de Estado de Bem-Estar se diferenciam pelo conjunto de políticas públicas ofertadas para atender demandas coletivas de sociedade, educação, saúde à assistência social, ou na proposição de Esping-Andersen, pelo grau de "desmercantilização" e "desfamilização" da proteção social.
} 
financiamento de suas funções estatais ${ }^{3}$. Em todos eles, censos, pesquisas amostrais e registros administrativos continuaram a ser implantados para responder às demandas mais complexas de gestão pública e da estrutura econômica, seja para promoção ativa de políticas públicas, seja para regulação do mercado provedor de serviços.

O fato é que a produção de indicadores sociais se deve, em boa medida, ao surgimento e estruturação do Estado de Bem-Estar Social e à consolidação das atividades de planejamento do setor público ao longo do século XX, em particular a partir dos anos 1960 (ATKINSON, 2005). Assim como a crise de 1929 gerou um ambiente propício para que, nas décadas seguintes, se concebessem os sistemas de contas nacionais, de registros e pesquisas para acompanhar a conjuntura econômica e o desemprego, a persistência da pobreza e desigualdade, mesmo em situações de ampliação da produção econômica, acabou evidenciando a necessidade de dispor de Sistemas de Indicadores Sociais para promover e acompanhar a mudança social (NEUFVILE, 1975). É nesse contexto que se empreendeu um imenso esforço conceitual e metodológico para o desenvolvimento de instrumentos de mensuração do bem-estar e da mudança social nas agências estatísticas dos diversos países, registrado na literatura como o 'Movimento de Indicadores Sociais' (CARLEY, 1985).

Os sistemas nacionais de produção e de disseminação de Estatísticas Públicas passaram a incorporar novas dimensões investigativas e a produzir relatórios sociais de forma sistemática. A partir da década de 1970, surgiram publicações sobre a temática que se tornariam regulares nos anos seguintes, como Social Trends na Inglaterra, o Données Sociales na França, Gesellschaftsliche Daten na Alemanha, o Social Indicators nos EUA, para citar alguns dos principais relatórios à época (SANTAGADA, 2007). No Brasil não foi diferente e, em 1979, foi lançado Indicadores Sociais: relatório 1979, publicação de 450 páginas de análises e tabelas. $O$ relatório cobria oito temas - população e famílias, divisão do trabalho, mobilidade ocupacional, distribuição de renda, despesa familiar, habitação, educação e saúde - tratados com base em várias pesquisas que o IBGE havia realizado nos anos 1970. Novos volumes da série Indicadores Sociais acabaram saindo nos anos seguintes, com uma periodicidade irregular até 1998 , quando se criou a Síntese de Indicadores Sociais, com escopo temático mais circunscrito ao que as estatísticas anuais poderiam disponibilizar.

\footnotetext{
${ }^{3}$ Estes países são referências dos modelos de Estado de Bem-Estar mencionados, na ordem: Estado Anglo-Saxão Liberal, Continental Conservador, Mediterrâneo Familista e Nórdico Socialdemocrata. Com exceção dos EUA, todos os demais tinham carga fiscal acima de $40 \%$ do PIB em 2014. Nos EUA, a carga fiscal estacionou nos 35\% do PIB nos anos 1970, abortando o projeto de constituição de políticas sociais mais abrangentes iniciado no Governo Lyndon Johnson. A retomada de tal iniciativa nas décadas seguintes por presidentes democratas - governos Clinton e Obama - não foi também bem-sucedida. Em contraste ao contexto de coesão e igualdade social na Suécia, tais escolhas da sociedade americana não estaria por trás do aumento da desigualdade social, da violência e intolerância? Estas são questões instigantes para o Brasil, onde a carga fiscal tem se mantido em 35\% do PIB desde começo dos anos 2000.
} 


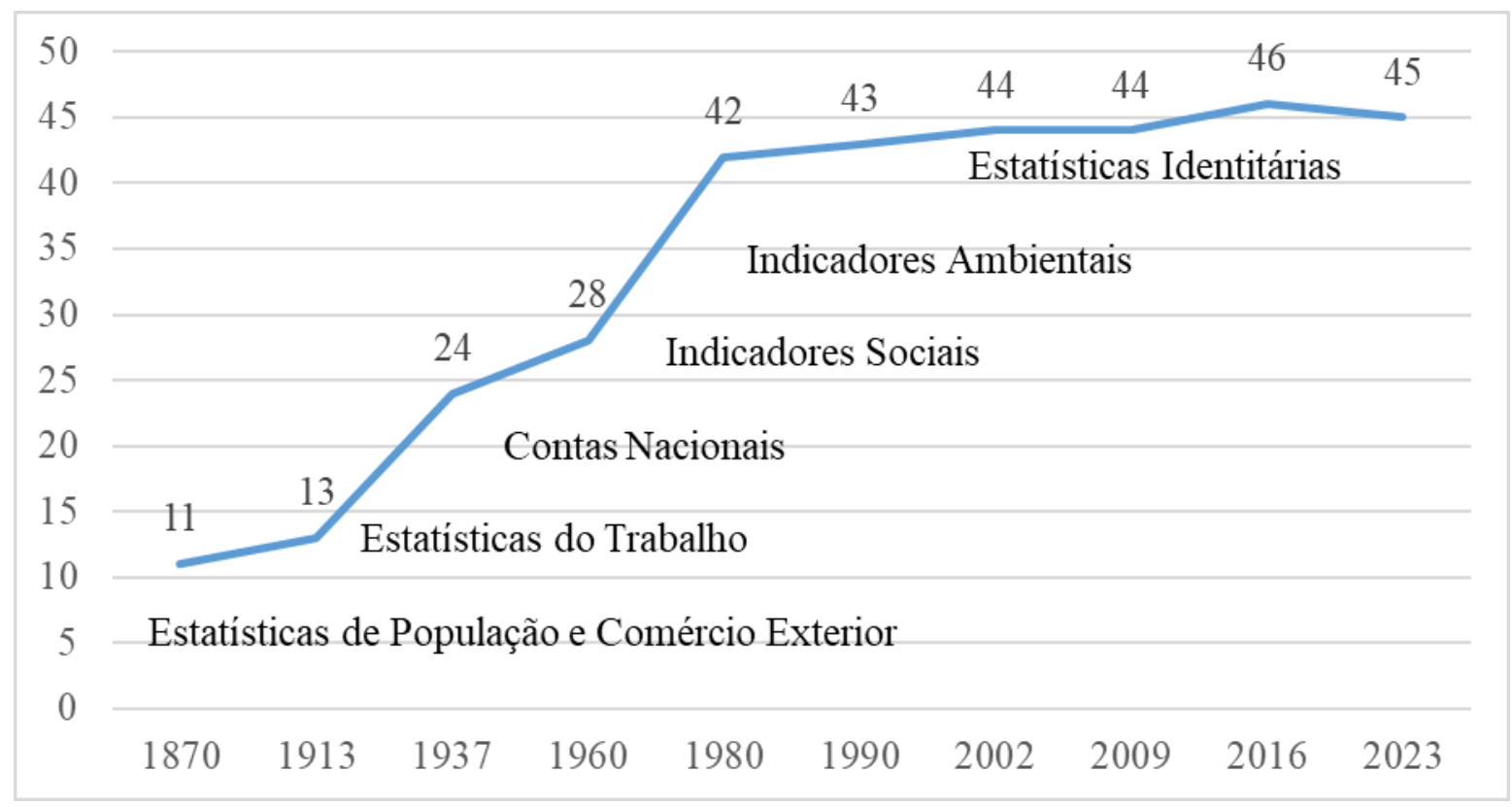

Figura 1. Estruturação do Estado de Bem-Estar (expresso pela Carga Fiscal) e a ampliação do escopo das Estatísticas Públicas. Fonte: Elaboração própria a partir de Tanzi (2005), Mauro et al (2013), IMF Fiscal Monitor (Tabela A5) ${ }^{4}$ e Jannuzzi (2017).

Nota: A Carga Fiscal ilustrada representa o percentual de tributos sobre o Produto Interno Bruto dos 11 países mais desenvolvidos da OCDE.

Em meados dos anos 1980, um novo 'Movimento dos Indicadores Sociais' começou a se espraiar pelo mundo, mobilizados pelas discussões suscitadas pela introdução do Relatório do Desenvolvimento Humano e, em especial, nos anos 1990, pelas várias Cúpulas Sociais Mundiais promovidas pelas agências temáticas das Nações Unidas, entre elas a Conferências Mundiais sobre Meio Ambiente (1992) e Desenvolvimento Social (1995). Criou-se uma ampla mobilização para promoção de políticas sociais nos países não desenvolvidos e de renda média, com menor ou maior escopo setorial e grau de cobertura populacional, que viriam a ser acompanhadas por pressão pela produção de novas estatísticas e relatórios sociais. É nesse contexto que se estabelece, em 2000, a Declaração dos Objetivos de Desenvolvimento do Milênio, uma agenda certamente minimalista em relação à agenda social discutida na década anterior, mas ainda assim impactante na produção de pesquisas e indicadores sociais.

Desde então, o aumento da desigualdade social na Europa e EUA, os dilemas entre crescimento econômico e uso dos recursos naturais, assim como a crise internacional de 2008, acabaram ensejando nova onda do 'Movimento', o terceiro, com maior repercussão mundial e maior amplitude temática. Foi nesse contexto que apareceu o Relatório da Comissão Stiglitz-SenFitoussi, que propunha revisão das medidas de desenvolvimento e bem-estar (STIGLITZ et al, 2014). Posteriormente, em 2012, fortalecem-se as discussões que culminaram com a proposição da agenda dos Objetivos de Desenvolvimento Sustentável, com desafios consideráveis na produção de indicadores de monitoramento (KOEHLER, 2016). Novas pesquisas e sistemáticas de registros de informação seriam necessárias para produzir indicadores que, de fato, pudessem

\footnotetext{
${ }^{4}$ Disponível em: <www.imf.org/ /media/Files/Publications/fiscal-monitor/2018/April/pdf/fm1801.ashx?la=en>. Acesso em: $15 / 06 / 2018$.
} 
acompanhar as mudanças sistêmicas da "boa" política pública preconizada nessa agenda, qual seja, a que simultaneamente geraria prosperidade econômica, inclusão social e sustentabilidade ambiental.

Sem negar a importância dessa agenda internacional de desenvolvimento ao longo das últimas décadas, no caso do Brasil, a produção de Estatísticas e Indicadores Sociais foi particularmente impactada por determinantes político-institucionais internos, em particular, a estruturação de políticas e programas ensejados pela Constituição Federal de 1988 (CASTRO, 2011). Afinal, novas políticas geraram novas demandas de informação para dimensionamento de demandas sociais, para elaboração de diagnósticos socioeconômicos, para monitoramento da implementação de políticas e programas e para avaliação de resultados e impactos dos mesmos. Indicadores, pesquisas e outras ferramentas informacionais passaram a ser cada vez mais necessários frente a crescente institucionalização do Planejamento Governamental e maior complexidade nos arranjos federativos de operação das políticas sociais.

Em um contexto de redemocratização, sindicatos e movimentos sociais passaram a fazer uso crescente de estudos e indicadores para fundamentar demandas por políticas. Estatísticas que permitam reconhecimento identitário - de negros, indígenas, quilombolas, população em situação de rua - passaram a ser cada vez mais demandadas e produzidas nos últimos anos. A mídia e outras organizações sociais vislumbraram o potencial jornalístico ou de pressão por transparência do gasto governamental (SAVIGNANO; JANNUZZI, 2003). A profissionalização da Administração Pública, nas três esferas de governo, foi mais um vetor impactante para que os Indicadores Sociais viessem a se tornar a "língua franca" no ciclo de formulação e avaliação de políticas de programas sociais.

É sintomático do uso intensivo dos indicadores na formulação de políticas públicas que o próprio Ministério de Planejamento tenha desenvolvido um manual de indicadores para programas e balanço anual de indicadores sociais (MPOG, 2010, 2013). Nesse contexto, o IBGE e outras instituições públicas ligadas ao sistema de planejamento - na esfera federal e subnacional passaram a ser pressionadas a produzir, compilar e disponibilizar um volume crescente de informação estatística, em bases mais periódicas e referidas a domínios territoriais e segmentos populacionais mais específicos. São reveladores desse processo de inovação na agenda de produção de informação estatística as reformulações conceituais e de questionário na Pesquisa Mensal de Emprego (PME) e da PNAD nos anos 1990, o surgimento da Pesquisa de Informações Básicas Municipais em 1999, as discussões sobre implementação de uma modalidade de Censo Contínuo, o amplo debate e desenho da PNAD Contínua nos anos 2000, a introdução da Pesquisa de Informações Básicas Estaduais em 2012 e da Pesquisa Nacional de Saúde (PNS) em 2013. Também deve ser mencionado como sintomáticos desse novo contexto entre Estatísticas e Políticas Públicas os esforços de diálogo do IBGE com representantes da academia, sociedade civil e Administração Pública, por ocasião dos Censos Demográficos 2000 e 2010 e a realização dos Encontros Nacionais de Produtores e Usuários de Estatísticas Sociais, Econômicas e Territoriais. Foram realizados três Encontros nos últimos 20 anos (1996, 2006 e 2016).

Enfim, estatísticas e indicadores sociais podem ser de grande utilidade para os diversos agentes e instituições envolvidos na definição das prioridades sociais e na alocação de recursos do orçamento público. Se bem empregados, os indicadores sociais podem enriquecer a interpretação empírica da realidade social e orientar de forma mais competente a análise, a 
formulação e a implementação de políticas sociais. Na negociação das prioridades sociais, os indicadores podem contribuir no apontamento da magnitude das carências a atender nas diversas áreas de intervenção. As escolhas são sempre difíceis, já que os recursos públicos são, em geral, sempre insuficientes para atender a totalidade dos problemas. Construir mais escolas, salas de aula ou quadras esportivas pode implicar a edificação de um número menor de moradias populares; aumentar e diversificar o atendimento médico e hospitalar pode cercear o alcance de programas de expansão de infraestrutura urbana para áreas ainda não atendidas; melhorar e subsidiar o transporte público pode concorrer com as necessidades de ampliação de vagas em creches e em asilos. Indicadores podem ajudar na formação de consensos sobre quais demandas devem ser priorizadas, auxiliar no diálogo com a sociedade e prover meios técnicos para justificar as decisões políticas.

\section{As PNADs e as Políticas de Desenvolvimento Social}

Com a entrega das últimas publicações de resultados no primeiro semestre de 2017, a PNAD encerrou seu ciclo de cinquenta anos de produção e disseminação de informações estatísticas para o Estado e Sociedade brasileiros. Implantada em 1967 com o objetivo de captar, principalmente, as mudanças conjunturais e estruturais do mercado de trabalho brasileiro, a pesquisa passou a contemplar, gradativamente, a investigação de várias temáticas de interesse da agenda das Políticas Públicas no país (IBGE, 2015). Assim, anualmente, além da aplicação do questionário padrão, em que se registravam informações sobre características demográficas e ocupacionais da mão de obra (rendimento, horas trabalhadas, situação de emprego, ocupação etc.), levantaramse, de forma suplementar, temas como trabalho infantil, situação do menor, ensino supletivo, acesso a serviços de saúde, acesso a programas sociais, vitimização, segurança alimentar e, mais recentemente, acesso às tecnologias da informação e comunicação, inclusão produtiva e cuidados da primeira infância.

Além de ampliar seu escopo investigativo nas últimas décadas, houve um alargamento sistemático da cobertura do seu universo de referência, levando, consequentemente, a aumento considerável da amostra (BIANCHINI; ALBIERI, 1999). Ao final da pesquisa, em 2015, a amostra contemplava mais de 130 mil domicílios, de modo a garantir a produção de indicadores consistentes em níveis geográficos mais desagregados. Assim, nos anos 1980, os resultados da PNAD passaram a ser divulgados para as cinco macrorregiões (N, NE, S, SE, CO), para os estados e para as nove regiões metropolitanas, com apenas $2,4 \%$ da população nacional fora do seu universo, residente na zona rural da antiga Região Norte. Essa parcela passou a ser investigada em 2004, tornando, de fato, a PNAD uma pesquisa com representatividade nacional.

Com tal escopo temático, abrangência territorial e periodicidade anual, a PNAD constituiuse em uma fonte privilegiada para a análise de tendências socioeconômicas e demográficas da população brasileira, para avaliação dos impactos das políticas econômicas adotadas e para registro das transformações estruturais do mercado de trabalho (OLIVEIRA; SIMÕES, 2005). As informações disponíveis anualmente sobre inserção ocupacional, perfil educacional, condições de 
moradia, características demográficas subsidiaram um volume incontável de estudos nas universidades brasileiras, no próprio IBGE, nos institutos de pesquisas como Ipea e Ibase, nas agências multilaterais como Cepal, PNUD, FAO e OIT, além de relatórios internacionais em outros países e vasta documentação usada na formulação e avaliação de políticas e programas públicos nos Ministérios. A PNAD tem sido imprescindível nas avaliações anuais do Plano Plurianual dos governos federal e estaduais, na produção de relatórios de acompanhamento das agendas de compromissos internacionais ou de desenvolvimento, como os Relatórios de Acompanhamento dos Objetivos do Milênio até 2015.

No que interessa mais especificamente a esse trabalho, vale destacar que as informações aportadas pela PNAD nos anos 2000 - coletadas no seu questionário básico e aquelas trazidas nos suplementos anuais - foram particularmente importantes para o desenho, aprimoramento e avaliação das Políticas de Desenvolvimento Social e, naturalmente, para os resultados expressivos de queda de pobreza, desigualdade e inclusão social. A possibilidade de construir indicadores mais específicos às intervenções de políticas e conjuntura - pelo amplo escopo temático da PNAD -, a extensão da série da pesquisa - cobrindo contextos econômicos e de políticas sociais bastantes distintos entre 1992 e 2014 -, e as descontinuidades observadas a partir de 2015, certamente contribuíram para o alcance desses resultados, pela ampliação da capacidade de gestão das mesmas. Como mostram as avaliações de programas públicos compilados por Pires e Gomide (2016), é cada vez mais importante considerar, no sucesso e insucesso dos mesmos, o alinhamento dos arranjos de implementação das ações, a capacidade técnica dos servidores envolvidos e a arquitetura institucional das políticas. No caso das Políticas de Desenvolvimento Social, Ferrarezi e Jannuzzi (2016) detalham outros aspectos associados e sugerem a importância de algumas das inovações introduzidas como determinantes da efetividade social observada.

Dentre estas inovações nas políticas e programas do MDS estaria um enorme esforço de articulação federativa e intersetorial na implementação das ações, além da organização de um sistema de gestão apoiado em volume expressivo de dados, indicadores e pesquisas, customizados para cada fase do ciclo de implementação dos programas (SAGI, 2016).

Afinal, seria necessário muito mais que "genuíno espírito republicano" e "desprendimento político-partidário" para que se pudesse alcançar resultados em diversas dimensões setoriais da política social, na intensidade da mudança e tempo requerido, considerando ainda a complexidade operacional das ações e escala numérica de agentes envolvidos no governo federal, estados, municípios e entidades envolvidas. Não houvesse, de um lado, cooperação intersetorial entre vários Ministérios e pactuação com seus congêneres em estados e municípios, e de outro, instrumentos razoavelmente sofisticados de gestão - entre eles, aqueles de desenho, monitoramento e avaliação de programas - dificilmente se conseguiria obter os impactos expressivos quanto à diminuição da pobreza e desigualdade e avanços quanto ao acesso a direitos sociais básicos pela população mais pobre, de Norte a Sul, pelo país, como mostrado em Campello et al (2014), Ipea (2014) ou na Síntese de Indicadores Sociais (IBGE, 2016). ${ }^{5}$

\footnotetext{
${ }^{5}$ Vide ainda, nesse sentido, o Estado da Insegurança Alimentar no Mundo (FAO 2014), Cepal (2015) e os Relatórios de Desenvolvimento Humano de 2011 a 2014, em que o Brasil é citados como um dos países que logrou alcançar resultados sociais expressivos, procurando mitigar externalidades ambientais do desenvolvimento e dentro dos princípios de governança democrática e participativa (PNUD 2014).
} 
O fato é que a capacidade técnica de gestão interfederativa das Políticas de Desenvolvimento Social contou com um componente informacional expressivo. Afinal, teria sido possível a superação da fome e da extrema pobreza no país se a temática não entrasse como prioridade política durante 12 anos, por meio de estratégias como o Fome Zero, Bolsa Família e Plano Brasil Sem Miséria, em que estatísticas sociais derivadas de pesquisas do IBGE foram usadas como evidências da necessidade e legitimidade das ações? Teria sido possível defender a necessidade e mérito do Programa Bolsa Família com toda campanha midiática contra o mesmo, sem as estimativas de população em insegurança alimentar que a PNAD levantou em três ocasiões entre 2004 e 2013? Teria sido possível garantir que o programa fosse expandido rapidamente nos anos 2000, sem perda de focalização entre os mais pobres, se não houvesse avaliações proporcionadas pelas estatísticas de pobreza e extrema pobreza derivadas da PNAD? Teria sido defensável advogar, frente às resistências das classes médias do Centro-Sul, pela necessidade de provimento de cisternas ou fomento ao produtor familiar sem estatísticas da pobreza rural no Nordeste?

A PNAD e outras pesquisas - do IBGE, da SAGI/MDS e de outros ministérios - disponibilizaram evidências empíricas que direta ou indiretamente se prestaram a defender a agenda de priorização políticas de combate à fome e pobreza entre 2003 e 2014. Contribuíram para dimensionamento da pobreza, caracterização socioeconômica e localização regional dos públicos vulneráveis à pobreza monetária - como as edições da PNAD dos anos 1990 a 2002 - e dos segmentos expostos à insegurança alimentar - dimensionados no suplemento da pesquisa de 2004. Permitiram a produção de indicadores de monitoramento do alcance das ações (pelos suplementos de acesso a programas sociais de 2004 e 2006 e do Cadastro Único de 2014), como também de avaliação da efetividade dos programas nos anos seguintes (pelas taxas de pobreza monetária e insegurança alimentar, a partir de dados do questionário básico e suplementos de 2009 e 2014). Rocha (2013) chega a sugerir que a PNAD foi determinante para garantir que o Programa Bolsa Família conseguisse alcançar a população mais pobre em seu processo de expansão de cobertura, ao permitir a avaliação da focalização do programa e a computação de taxas anuais de pobreza e extrema pobreza.

Para além desses usos instrumentais da pesquisa em atividades de gestão, os dados da PNAD permitiram o MDS enfrentar em bases técnicas a disputa política e as resistências à implantação de suas políticas, no parlamento, na mídia e nas classes médias. Uma análise de conteúdo dos editoriais e matérias jornalísticas, na mídia impressa e televisiva, seria muito esclarecedora para registrar a regularidade com que foram produzidas informações equivocadas - até mesmo factoides - acerca do Bolsa Família e de seus beneficiários. Mitos acerca do efeitonatalidade ("O programa estimula mulheres a terem mais filhos, para aumentar o valor dos benefícios"), do efeito-preguiça ("O programa estimula a vagabundagem"), dos descontroles na concessão de benefícios ("O programa é usado para compra de votos de eleitores") estão entre os mais recorrentes, em que pesem evidências robustas em contrário, baseadas na PNAD e outras fontes, reunidas em livro comemorativo de 10 anos do programa, com participação de diversos pesquisadores do Brasil e exterior (NERI; CAMPELLO, 2013).

O "contencioso" entre IBGE e a equipe do Fome Zero acerca dos resultados de baixo grau de desnutrição de crianças pela Pesquisa de Orçamentos Familiares (POF) 2002/2003, descrito por Bello (2013), foi mais um desses episódios de desinformação que políticas públicas vivenciaram, prisioneiras da restrita pluralidade de opiniões veiculada nos meios de comunicação no país. 
Fato é que, ao contrário do veiculado na mídia à época, a fome ainda era um espectro na vida de parte significativa de famílias brasileiras. A estatísticas de subalimentação da FAO apontavam mais de $15 \%$ de subalimentados no Brasil ao final dos anos 1990 (FAO, 2014), cifra que o suplemento sobre Segurança Alimentar encartado na PNAD 2004, já citado, acabou corroborando. A pesquisa apontou que a insegurança alimentar moderada e grave acometiam cerca de $19 \%$ dos domicílios do país. Se a desnutrição infantil crônica medida pelos indicadores antropométricos da POF já havia diminuído significativamente - por ações públicas em nutrição e merenda escolar, estruturadas desde os anos 1970, vale registrar - a fome em sentido mais amplo - insegurança de disponibilidade de recursos para compra de alimentos, além da privação de consumo de dieta adequada em termos de quantidade e qualidade - ainda era uma realidade para parte significativa da população adulta. Combate à fome e extrema pobreza eram, sim, pelos indicadores sociais disponíveis, uma agenda necessária e prioritária nas políticas públicas do começo do século XXI. Indicadores de pobreza monetária calculados na série PNAD de 2004 a 2014 e os suplementos de Segurança Alimentar, replicados em 2009 e 2013, puderam demonstrar a importância e efetividade dessa agenda.

Talvez não haja demonstração mais emblemática da contribuição da PNAD como instrumento de apoio às decisões em políticas públicas que os suplementos encartados em suas duas últimas edições. Em 2014, para captar os efeitos da ampliação da escala e escopo das ações de qualificação profissional no país, assim como de inclusão produtiva, foram elaborados questionários temáticos específicos, em cooperação conjunta do MDS e Ministério da Educação. Nesse mesmo ano, dois outros suplementos foram coletados: um inédito, para avaliar cobertura e foco do Cadastro Único para Programas Sociais do Governo Federal e outro sobre Mobilidade Social, para captar informações de filhos, além de chefes de domicílios e cônjuges. Na última edição da PNAD, em 2015, coletou-se informações mais detalhadas sobre acesso e permanência de crianças em creches e outros arranjos, por meio de suplemento sobre "Primeira Infância".

Antes de finalizar essa seção, não se pode deixar de comentar sobre a contribuição de outras pesquisas do IBGE, além da PNAD, para as políticas e os programas do MDS. Em 2012, a SAGI/MDS ajudou a realizar a primeira Pesquisa de Informações Básicas Estaduais (ESTADIC), que investigou aspectos da estrutura administrativa da Assistência Social e Segurança Alimentar nas 27 Unidades da Federação. No ano seguinte, diversos aspectos acerca da implementação do Sistema Único da Assistência Social (SUAS) foram novamente investigados por meio da Pesquisa de Informações Básicas Municipais (MUNIC), atualizando o retrato realizado em 2005 e 2009. Nova edição da Pesquisa de Entidades da Assistência Social (PEAS) foi realizada em 2013/2014, aprofundando o diagnóstico do levantamento anterior (2006) acerca da capacidade de atendimento das instituições privadas conveniadas do SUAS. Sem essas pesquisas, teria sido possível pactuar compromissos e metas de atendimento de serviços socioassistenciais sem instrumentos que permitissem acompanhar a estruturação física da rede pública e privada nos municípios? Sem tal expansão física, teria sido possível ampliar a capilaridade das operações do Cadastro Único e registrar a população potencialmente beneficiária do Programa Bolsa Família e do Benefício de Prestação Continuada?

De forma a fortalecer e repensar as políticas de Segurança Alimentar e Inclusão Produtiva no MDS, em 2014, a ESTADIC e MUNIC encartaram suplementos sobre a estrutura institucional e administrativa dessas políticas nos estados e municípios. Essas pesquisas trazem um diagnóstico 
inédito para desenho de intervenções públicas mais integradas nessas áreas programáticas, que se imaginava que teriam sua maturação no plano que se seguiria ao Brasil Sem Miséria. As "portas de saída" para população mais pobre ainda estão por serem ampliadas no país, demandando desenho de programas mais customizados e adequados às dinâmicas econômicas locais e perfis socioeconômicos dos públicos-alvo. Essas pesquisas permitem conhecer a capacidade de implementação de programas voltados a esse desafio na esfera subnacional. Por disporem de séries históricas e permitirem algum dimensionamento da capacidade de gestão e oferta de serviços pelos estados, estas pesquisas - ESTADIC, MUNIC e PEAS - podem fornecer parâmetros interessantes para a interpretação da contribuição específica das políticas sociais implementadas, seja em uma abordagem descritiva, modelagem econométrica ou micro-simulação.

O Censo Demográfico de 2010 foi particularmente importante para garantir a efetividade das ações de busca ativa de famílias em situação de maior vulnerabilidade para o Plano Brasil Sem Miséria, de localização das áreas prioritárias para atendimento do Programa Mais Médicos e de construção de equipamentos esportivos e de lazer pelo Ministério dos Esportes nos municípios brasileiros entre 2011 e 2014 (JANNUZZI et al, 2014). Pelo fato de dispor de informações sobre rendimento de todos os membros do domicílio no questionário básico, foi possível computar a renda domiciliar em nível de setor censitário, permitindo, assim, a micro-territorialização de Políticas Públicas. É certamente preocupante que se venha perder essa possibilidade com as mudanças anunciadas para o Censo Demográfico 2020.

Enfim, a PNAD, MUNIC, Censo e outras pesquisas fizeram diferença no processo de desenho, monitoramento e avaliação das Políticas de Desenvolvimento Social. É certo que a mudança social relevada por diversos indicadores e concretamente vivenciado por milhões de brasileiros certamente seria diferente se não houvesse tido uma clara aposta e determinação política de assegurar aumento real do salário mínimo; de aportar volume crescente de recursos para ampliação da cobertura de políticas sociais; de criar e rapidamente expandir programas voltados à superação de situações de fome e pobreza pelo país. Mas as políticas públicas não teriam produzido esse impacto social se não houvesse um claro aprimoramento da capacidade de planejamento, gestão e avaliação de políticas públicas no país, e nesse processo, o uso intensivo da informação estatística e de pesquisas. Se os indicadores sociais foram insumos essenciais para formulação e aprimoramento das políticas públicas nos últimos vinte anos, eles também revelaram o quadro de iniquidades ainda existente no país, colocando os desafios a pautar a ação pública para os próximos vinte anos.

\section{À guisa de conclusão: das evidências estatísticas à midiotização das Políticas Pú- blicas}

Esse texto procurou trazer subsídios para ilustrar um caso em que a lógica virtuosa e auto reforçadora entre Estatísticas e Políticas Públicas orientada por evidências, em que demandas mais sofisticadas de diagnósticos e desenho de políticas e programas requereram e viabilizavam pesquisas mais detalhadas, que, com seus indicadores derivados, mais específicos, conduziram a mudanças incrementais e inovações nas políticas e programas. É preciso reconhecer que essa tese requer mais pesquisa e evidenciação, por meio de entrevistas com pesquisadores dos Siste- 
ma Estatístico e técnicos e gestores envolvidos na formulação e avaliação das Políticas Públicas. Estudos de caso, de uso de pesquisas em situações concretas como a aqui apresentada, e análises bibliométricas, de contabilização do uso de pesquisas do IBGE em documentos oficiais e relatórios técnicos - como empregado no esforço de avaliação da efetividade das atividades da SAGI (SAGI, 2016) -são outras estratégias ${ }^{6}$.

Se, em contextos democráticos, os indicadores se prestam a iniciar discussões e organizar narrativas sobre efetividade ou não das políticas públicas, em contextos tecno-plutocráticos, indicadores podem encerrar a discussão, ao se atribuir "sobre-legitimidade" política a avaliações de caráter técnico. Indicadores e informação estatística expressam, em última análise, os valores subjacentes às concepções de Estado e da função das políticas públicas (JANNUZZI, 2016). Como qualquer recurso técnico, indicadores podem ser utilizados de forma construtiva ou irresponsável. Podem informar ou desinformar. O bom uso gera conhecimento relevante para análise da mudança social ou ação governamental. O mau uso ou abuso produz informação equivocada ou factoide, sob aparente verniz técnico. Podem contribuir para aprimorar políticas e programas ou serem empregados para deslegitimá-los, como se tem visto com certa regularidade na mídia brasileira.

Se os desígnios das Políticas Públicas passaram a ser influenciados - e, em vários casos, até definidos - nos tribunais do Judiciário e nos escritórios dos órgãos de controle - para sorte e azar das mesmas -, mais recentemente passaram a depender das reuniões de pauta da imprensa. Para além da judicialização, políticas públicas têm sido sujeitas a uma "midiotização" crescente, isto é, as políticas públicas têm sido reféns de debates superficiais, de baixa pluralidade e - vale enfatizar - idiotizado nos veículos de comunicação e nas mídias sociais. Têm sido submetidas a avaliação em "praça pública sem direito ao justo processo" técnico-político, em que articulistas generalistas, apoiados por seus especialistas consultados, impõem interpretações que, com frequência, deslegitimam políticas e programas meritórios, sem possibilidade de exposição do contraditório pelos formuladores ou gestores das mesmas ${ }^{7}$. Na realidade, o quadro é pior ainda, pois o julgamento sumário sequer se inicia, com a propagação robotizada de matérias claramente falsas ou inconsistentes pelas mídias sociais, que parecem apostar na construção de "verdades" a partir da frequência de repetição e alcance desses conteúdos midiotizados.

O poder da mídia em pautar assuntos, reverberar determinados temas - e ocultar outros enquadrá-los como notícias e construir narrativas positivas ou negativas sobre os mesmos é uma questão já conhecida e reconhecida na Ciência Política (AZEVEDO, 2004). Mas parece que no Brasil, esse poder é muito maior que em outras democracias ocidentais, pelo que sugere Haddad (2017). Em um contexto de forte concentração empresarial dos meios de comunicação e um

\footnotetext{
${ }^{6}$ Vale observar que no documento do Plano Nacional de Educação, por exemplo, são mencionadas as pesquisas do IBGE e de outras fontes que deverão ser usadas para cômputo dos indicadores. Há, nesse caso, uma clara evidenciação entre Estatística e Política Pública.

${ }^{7}$ O Programa Nacional de Acesso ao Ensino Técnico e o programa de ampliação de jornada escolar em escolas de alunado de baixa renda (Mais Educação) são bons exemplos de políticas públicas meritórias vitimadas, em boa medida, pela "midiotização" das políticas públicas, Reportagens ilustrativas da campanha de deslegitimação por que esses programas passaram podem ser consultados em O Globo de 25/09/2015, p.26, na matéria cuja manchete e subtítulo é "Pronatec é irrelevante para o mercado: Ministério da Fazenda mostra que cursos não interferem na reinserção de empregados"; e no O Estado de São Paulo de 6/10/2015, p.A16, na matéria "Mais Educação não melhora nota dos alunos: É o que mostra estudo sobre programa federal para jornada integral; houve ainda queda em Matemática".
} 
quase "oligopólio opinativo" - em que os mesmos "meia-dúzia" de articulistas se revejam em "meia-dúzia" de programas na televisão aberta, fechada, rádio e colunas em jornais, impressos e online - fica difícil apresentar interpretações alternativas e concorrentes acerca de fatos e resultados de pesquisas. É o que Campos et al (2013) mostram no debate sobre a legitimidade e efetividade das políticas de cotas na mídia impressa, travado nesse contexto de plutocratismo opinativo, apoiado mais em julgamentos pré-concebidos do que em evidências empíricas - da PNAD inclusive - que teimavam - e teimam - em mostrar a persistência da discriminação no acesso à educação superior e mobilidade no mercado de trabalho por parte de negros no país. Vale também registrar que os depoimentos de vários ex-presidentes do IBGE, trazidas em Senra et al (2015), parecem demonstrar que a relação com a imprensa chega a ser mais tensa que com próprios órgãos de governo na história recente da instituição, seja pela dificuldade técnica de entendimento dos resultados das pesquisas, seja pela insistência do jornalista ou repórter na interpretação articulada - ou pautada - previamente, mesmo quando evidências complementares das pesquisas não a corroboram.

Não há dúvida do papel relevante e indispensável da imprensa no debate sobre méritos e deméritos das políticas públicas. Mas há que se reconhecer que, no caso da mídia brasileira, há muito por se trilhar para garantir profundidade analítica e pluralidade de apreciações sobre fatos e resultados acerca das políticas públicas. Enquanto o jornalismo científico, cultural e o econômico acabaram exigindo a contratação de profissionais com maior especialização profissional, as temáticas de políticas públicas - e estatísticas - continuam sendo cobertos por jornalistas e analistas de Conjuntura Política. Pela relevância e complexidade das intervenções públicas e as implicações políticas dos debates travados na imprensa, as políticas educacionais, sociais, de trabalho ou de saúde - e suas estatísticas e indicadores - mereceriam análises mais cuidadosas, aprofundadas e plurais. Mesmo quando reportagens acerca de resultados de políticas públicas trazem alguma densidade analítica e equilíbrio de posições antagônicas, as manchetes e subtítulos de apelo "midiático" podem causar danos expressivos na legitimidade, desenho e operação das políticas públicas. Enfim, jornalismo de políticas públicas é tão diferente de jornalismo político como Policy o é de Politics, como há muito se sabe em Ciência Política ou Administração Pública.

"Política Pública orientada por evidências" está longe de ser uma atividade estritamente objetiva e neutra, conduzida por tecnocratas iluminados e insuspeitos. Tampouco, as Políticas Públicas não podem ser guiadas por aparências e percepções do senso comum. A avaliação da relevância e mérito das Políticas Públicas não pode ficar restrita ao corpo técnico de governo, ao parlamento, órgãos de controle, judiciário ou aos robôs da mídia social. Precisa envolver a sociedade, por meio da mídia e de outros instrumentos de publicização das evidências e narrativas disponíveis, para que o debate sobre as Políticas seja o mais amplo, técnico e plural possível.

IBGE, INEP (Instituto Nacional de Estudos e Pesquisa Educacionais), INPE (Instituto Nacional de Pesquisas Espaciais), Fundação Osvaldo Cruz, IPEA, institutos estaduais de estatísticas têm cumprido papel fundamental nesse sentido, com a produção e a disseminação de informações técnicas sobre alcances, limitações e lacunas das Políticas Públicas no Brasil. Levantamentos de grande porte e complexidade como Censos Demográficos, Pesquisas Nacionais, Censo Escolar, Avaliação Educacional, Monitoramento Ambiental por sensoriamento 
remoto, Levantamento sobre Uso de Drogas constituem um legado informacional construído com muito esforço técnico e recursos públicos.

Propostas de mudanças nesses instrumentos precisam ser discutidas com tempo necessário, com responsabilidade técnica, com o reconhecimento da relevância instrumental e da legitimidade político-institucional que pautaram a construção dos mesmos. 
Referências

ATKINSON, T. et al. Social indicators: the EU and Social Inclusion. Oxford: Oxford Univ.Press, 2005.

AZEVEDO, F.A. Agendamento da Política. In RUBIM, A.A.C. (org) Comunicação e política: conceitos e abordagens. Salvador : Edufba, 2004.

BELLO, L.A. A mídia e os órgãos oficiais de estatísticas. Rio de Janeiro, 2013 (Dissertação de Mestrado ENCE/IBGE).

BIANCHINI, Z. M.; ALBIERI, S. Uma revisão dos principais aspectos dos planos amostrais das pesquisas domiciliares realizadas pelo IBGE. Revista Brasileira de Estatística, Rio de Janeiro, v. 60, n. 213, p.7-23, 1999.

CAMPELlO, T.; FALCÃO, T.; COSTA. P. V. (Orgs.). O Brasil Sem Miséria. Brasília, DF: MDS, 2014, p.793-822.

CAMPOS, L.A.; FERES Jr., J.; DAFLON, V.T.; Administrando o debate público: O Globo e a controvérsia em torno das cotas raciais. Revista Brasileira de Ciência Política, n¹1, pp. 7-31, maio - agosto de 2013.

CARLEY, M. Indicadores sociais: teoria e prática. Rio de Janeiro: Zahar, 1985.

CASTRO, J.A. Política Social no Brasil: marco conceitual e análise da ampliação do escopo, escala e gasto público. Revista Brasileira de Monitoramento e Avaliação, Brasilia,1:66-95, 2011.

CEPAL. Desarrolo Social Inclusivo. Santiago, 2015.

ESPING-ANDERSEN, G. As três economias do Welfare State. Lua Nova n. 24. 1991, p. 85-115.

FAO. State of Food Insecurity in the World. Rome, 2014.

FERRAREZI, E.R.; JANNUZZI, P.M. Por um programa de investigação de políticas sociais complexas: uma proposta metodológica e aplicação para análise do Plano Brasil Sem Miséria.

Cadernos de Estudos Desenvolvimento Social em Debate, n.25, p.262-295, 2016.

HADDAD, F. Vivi na pele o que aprendi nos livros. Piauí, n.129, p.28-37, junho 2017.

IBGE. PNAD: Um registro histórico 1967-2015. Rio de Janeiro, 2015.

Síntese de Indicadores Sociais. Rio de Janeiro, 2016.

. Indicadores Sociais: $\mathbf{4 0}$ anos de história. Rio de Janeiro, 2017.

IPEA. Objetivos de Desenvolvimento do Milênio: $5^{\circ}$. Relatório Nacional de Acompanhamento. Brasília, 2014.

JANNUZZI, P.M. Eficiência econômica, eficácia procedural ou efetividade social: Três valores em disputa na Avaliação de Políticas e Programas Sociais. Desenvolvimento em Debate, v.4, n.1, 2016, p. 117-142.

JANNUZZI, P.M. Indicadores Sociais no Brasil: conceitos, fontes de dados e aplicações. Campinas: Alínea, 6ª edição revista e ampliada, 2017. 
JANNUZZI, P.M.; NAKASHIMA, C.; BRASILEIRO, C.E.; SANTANA, C.H.A. Construindo Mapas de Pobreza, Serviços Públicos e de Oportunidades para o Plano Brasil Sem Miséria. Cadernos de Estudos - Secretaria de Avaliação e Gestão da Informação, v. 19, p. 78-87, 2014.

KOEHLER, G. Looking back and looking foward: the case for a development welfare state. In: Alberto Cimadamore, Gabriele Koehler, Thomas Pogge. (Org.). Poverty and the Millennium Development Goals. 1ed.Londres UK: Zed Books, v. 1, p. 229-257, 2016.

MAURO, P. et al. A Modern History of Fiscal Prudence and Profligacy. IMF Working Paper 13/5, 2013.

MILES, I. Social indicators for human development. New York: St. Martin's Press, 1985.

MORENO, L. et al. Los sistemas de bienestar europeos tras la crisis económica. Madrid: EuroSocial/IILA, 2014.

MPOG. Guia de elaboração de indicadores para programas. Brasília, 2010. Indicadores de Desenvolvimento Brasileiro. Brasília, 2013.

NERI, M. CAMPELLO, T. Programa Bolsa Família: uma década de inclusão e cidadania. Brasília, DF: IPEA, 2013.

NEUFVILLE, J. Social Indicators and Public Policy. New York: Elsevier, 1975.

OLIVEIRA, L.A.P.; SIMÕES, C.C.S. O IBGE e as pesquisas populacionais. Revista Brasileira de Estudos da População, São Paulo, vol 22., n. 2, p. 291-302, jul./dez. 2005.

OLIVEIRA, J.S. "Brasil mostra a tua cara": imagens da população brasileira nos censos demográficos de 1872 a 2000. Textos para discussão - Escola Nacional de Ciências Estatísticas. Rio de Janeiro, 2003.

PIRES, R.R.C.; GOMIDE, A.A. Governança e capacidades estatais: uma análise comparativa de programas federais. Rev. Sociol. Política., v. 24, n. 58, p. 121-143, jun. 2016.

PNUD. Relatório de Desenvolvimento Humano. Nova York, 2014.

ROCHA, S. Transferências de renda no Brasil: o fim da pobreza? Rio de Janeiro: Elsevier, 2013.

ROSSI, P.; DWECK, E. Impactos do Novo Regime Fiscal na saúde e educação. Cad. Saúde Pública, 32(12):1-5, 2016.

SAGI. Informação e Conhecimento para as políticas de desenvolvimento social. Brasília, 2016.

SANTAGADA, Salvatore. Indicadores Sociais: uma primeira abordagem histórica. Pensamento Plural, Pelotas n. 01, p. 113 - 142, jul.-dez.2007

SENRA, N. O saber e o poder das estatísticas. Rio de Janeiro: IBGE, 2005.

SENRA, N. et al. O Desafio de retratar o país: entrevistas com os presidentes do IBGE no período de 1985 a 2015. Rio de Janeiro, IBGE, 2015.

SENRA, N.; Tradição \& renovação: uma síntese da história do IBGE. Rio de Janeiro, IBGE, 2 ed.,2017. 
SAVIGNANO, V. N. M.; JANNUZZI, P. M. Disseminação de informação para a cidadania no Brasil: uma análise da cobertura das matérias sobre indicadores sociais na mídia impressa. Transinformação, v. 15, n. 3, 2003.

STIGLITZ, J.E.; SEN, A.; FITOUSSI, J.P. Mis-mesuring our lives: why GDP doesn't add up. New York, New Press, 2014.

TANZI, V. The economic role of the state in the 21st Century. Cato Journal, Vol. 25, No. 3, p.617638, 2005. 